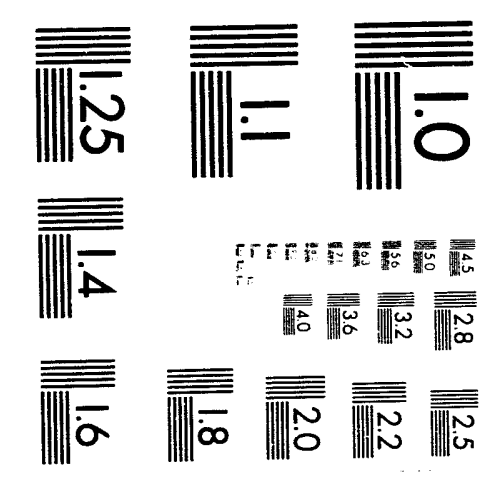



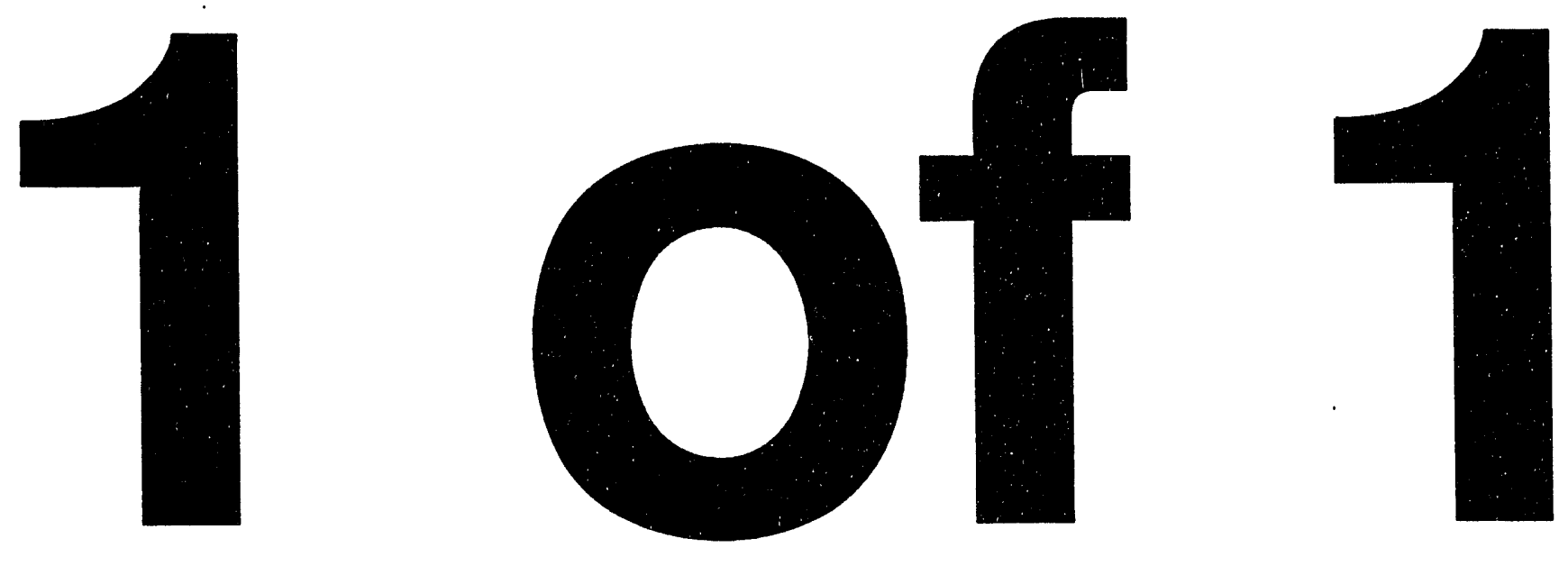
DOE/ER/13538-8

\title{
METALLOCARBOXYLATE CHEMISTRY
}

\author{
Progress Report/Continuation Proposal
}

November 17, 1992-November 22, 1993

\author{
Dorothy H. Gibson \\ Department of Chemistry \\ University of Louisville \\ Louisville, Kentucky 40292
}

November 22, 1993

\section{PREPARED FOR THE U.S. DEPARTMENT OF ENERGY UNDER GRANT NUMBER DE-FG05-86ER13538}

\section{DISCLAIMER}

This report was prepared as an account of work sponsored by an agency of the United States Government. Neither the United States Government nor any agency thureof, nor any of their employees, makes any warranty, express or implied, or assumes any legal liability or responsibility for the accuracy, completeness, or usefulness of any information, apparatus, product, or process disclosed, or represents that its use would not infringe privately owned rights. Reference herein to any specific commercial product, process, or service by trade name, trademark, manufacturer, or otherwise does not necessarily constitute or imply its endorsement, recommendation, or favoring by the United States Government or any agency thereof. The views and opinions of authors expressed herein do not necessarily state or reflect those of the United States Government or any agency thereof. 


\section{METALLOCARBOXYLA'TE CHEMISTRY}

\section{Progress report, 1992-93}

Our research is presently focused on bimetallic compounds of late transition metals with carbon dioxide or $\mathrm{CO}_{2}$-containing bridging ligands. The compounds represent models for catalytic intermediates in $\mathrm{CO}_{2}$ fixation/activation processes. With a moderate number of compounds now characterized, we are beginning to make structure-activity correlations.

In the last report, we outlined some initial observations on the thermolysis behavior of a newly characterized $\mu_{2}-\eta^{2}-\mathrm{CO}_{2}$-bridged complex, $\mathrm{CpFe}(\mathrm{CO})\left(\mathrm{PPh}_{3}\right)\left(\mathrm{CO}_{2}\right) \operatorname{Re}(\mathrm{CO})_{4}\left[\mathrm{P}\left(\mathrm{OEt}_{3}\right](\mathrm{A})\right.$. We now know that thermolysis of $\mathrm{A}$ at low temperatures, in solution, gives the carbene complex B (see attached scheme); $B$ has been crystallographically characterized (see attached figure). B is stable to further thermolysis unless $\mathrm{CO}$ is available; with $\mathrm{CO}, \mathrm{B}$ gives the same thermolysis products as those obtained from $\mathrm{A}$ in high temperature reactions (CE). At room temperature, $\mathrm{B}$ in the presence of $\mathrm{CO}$ slowly reverts to $\mathrm{A}$. The final product of thermolysis is $\mathrm{E}$ which has been isolated and characterized by elemental analysis and spectral data. Cleavage of $\mathrm{E}_{3}$ by $\mathrm{HBF}_{4}$ gives $\mathrm{CpFe}(\mathrm{CO})_{2}\left[\mathrm{P}\left(\mathrm{OEt}_{3}\right]+\mathrm{BF}^{-}\right.$, confirming that $\mathrm{E}$ (and its precursor $\left.\mathrm{D}\right)$ result from phosphorus ligand exchange on the iron and rhenium centers. Throughout the rearrangements, the $\mathrm{CO}_{2}$ bridging group remains intact! How the ligand exchange takes place will require further work (which is in progress).

Structure work on the indenyl iron complex, $\left(\eta^{5-}\right.$ $\left.\mathrm{C}_{9} \mathrm{H}_{7}\right) \mathrm{Fe}(\mathrm{CO})\left(\mathrm{PPh}_{3}\right)\left(\mathrm{CO}_{2}\right) \mathrm{SnPh}_{3}$, has been completed (and published; see 


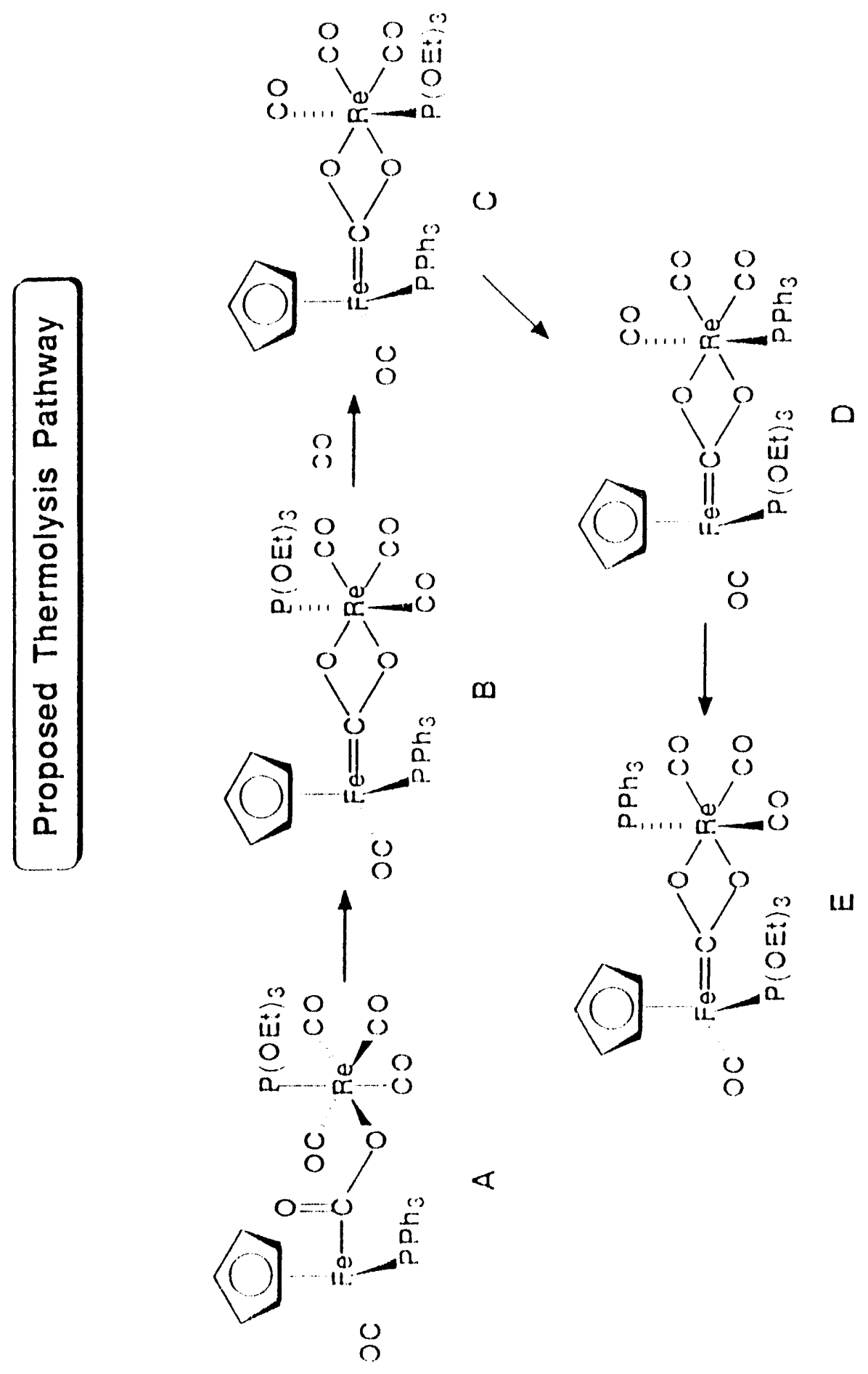




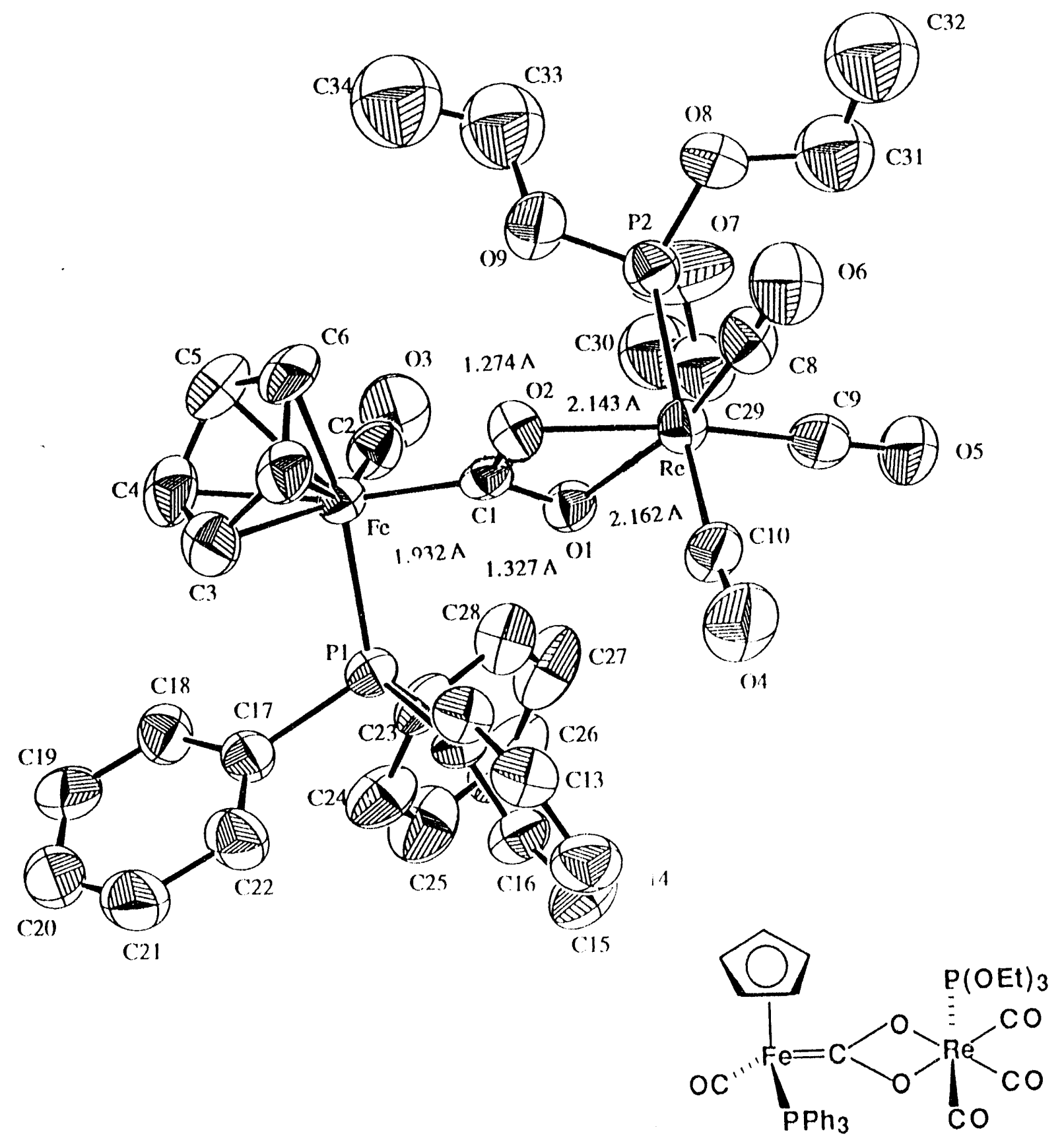


attachment); it shows severe distortions of the $\mathrm{CO}_{2}$ bonding parameters as compared to other similar compounds, resulting from the steric demands of the indenyl ligand. Unfortunately we have not been able to make other $\mathrm{CO}_{2}$ bridged complexes from this system since we can generate it in aqueous solution only.

We have synthesized and characterized a new metallocarboxylic acid, $\mathrm{Cp} * \operatorname{Re}(\mathrm{CO})(\mathrm{NO}) \mathrm{COOH}$, and we have found that it can be used directly with other reagents to generate $\mathrm{CO}_{2}$-bridged complexes as shown below:

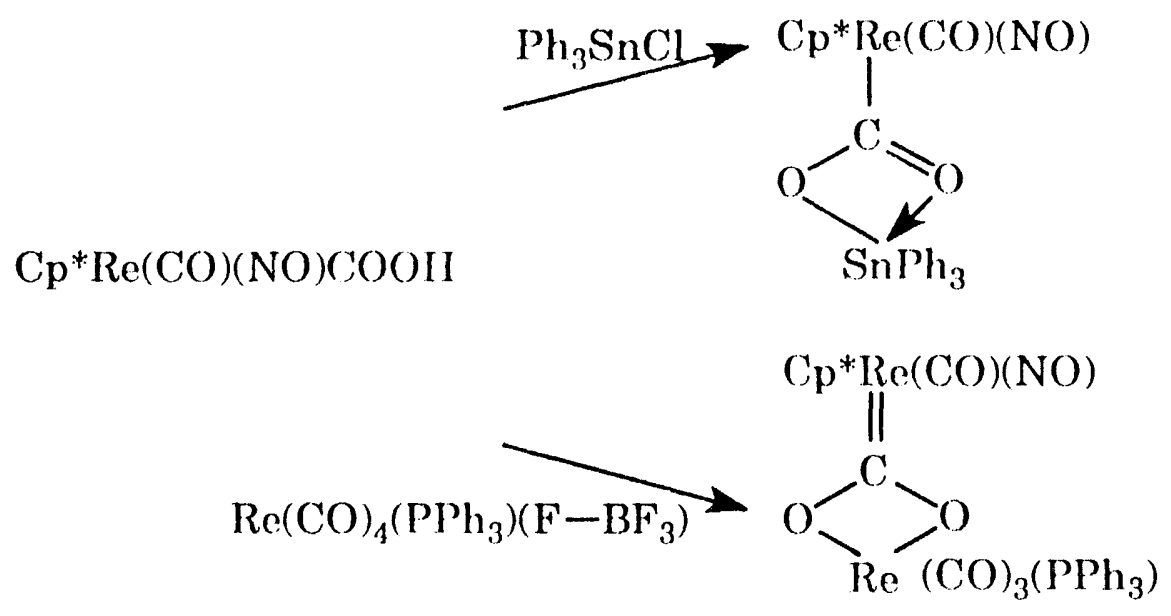

Both bimetallic products have been characterized fully, including their X-ray crystal structures (see attachments). Most interesting is the fact that the rhenium-rhenium complex is of the $\mu_{2}-\eta^{3}$ type, formed without an observable $\mu_{2-}$ $\eta^{2}$ precursor; enhanced nucleophilicity of the carboxylate intermediate is believed to be responsible.

After trying unsuccessfully to extend our work on iron-iron carboxyethylene bridged complexes (reported earlier: Organometallics, 11, 1993, 1992) to systems containing alkyne or diene groups, we have chosen to probe reactions of the new rhenium metallocarboxylate as outlined below: 
Figure 1. ORTEP drawing of 3 with thermal ellipsoids shown at the $50 \%$ probability level. Selected bond distances $(\AA)$ and bond angles (deg) are as follows: Re-C(1), 2.100(9); C(1)-O(1), 1.322(9); C(1)-O(2), 1.24(1); O(1)-Sn, 2.092(3); O(2)-Sn, 2.399(1); $\mathrm{O}(1)-\mathrm{C}(1)-\mathrm{O}(2), 114.6(7) ; \mathrm{Re}-\mathrm{C}(1)-\mathrm{O}(1), 119.4(6) ; \mathrm{Rc} . \mathrm{C}(1)-\mathrm{O}(2), 126.0(6)$; $\mathrm{O}(1)-\mathrm{Sn}-\mathrm{O}(2), 56.79(5)$ 


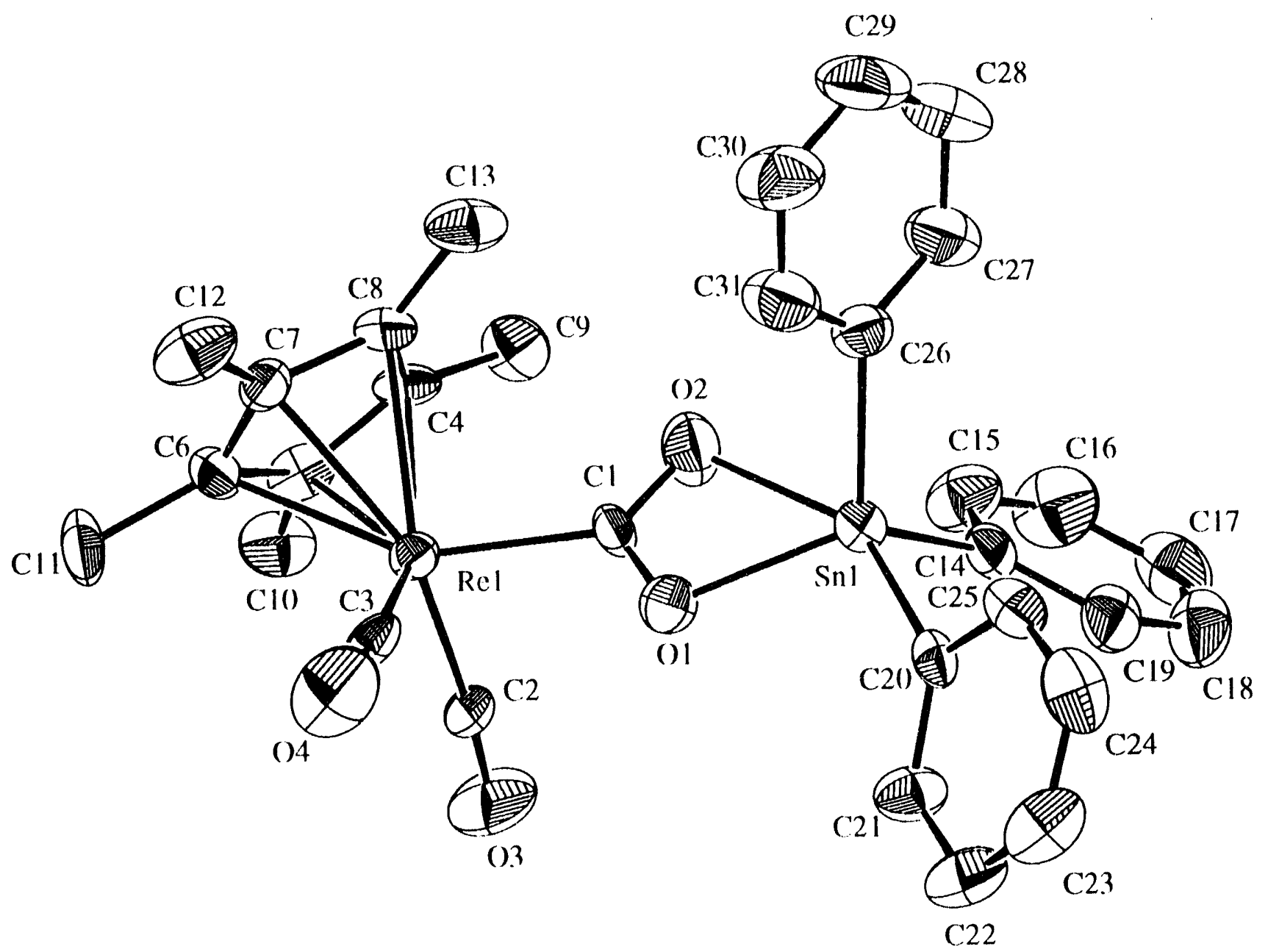


Figure 2. ORTEP drawing of 4 with thermal ellipsoids shown at the $50 \%$

probability level. Selected bond distances $(\AA)$ and bond angles (deg) are as follows:

$\operatorname{Re}(1)-\mathrm{C}(1), 2.089(6) ; \mathrm{C}(1)-\mathrm{O}(1), 1.296(6) ; \mathrm{C}(1)-\mathrm{O}(2), 1.289(8) ; \mathrm{O}(1)-\operatorname{Re}(2), 2.165(4) ;$

$\mathrm{O}(2)-\operatorname{Re}(2), 2.175(3) ; \mathrm{O}(1)-\mathrm{C}(1)-\mathrm{O}(2), 113.2(5) ; \operatorname{Re}(1)-\mathrm{C}(1)-\mathrm{O}(1), 122.0(4) ;$

$\operatorname{Re}(1)-C(1)-O(2), 124.8(3) ; O(1)-\operatorname{Re}(2)-O(2), 59.6(1)$ 


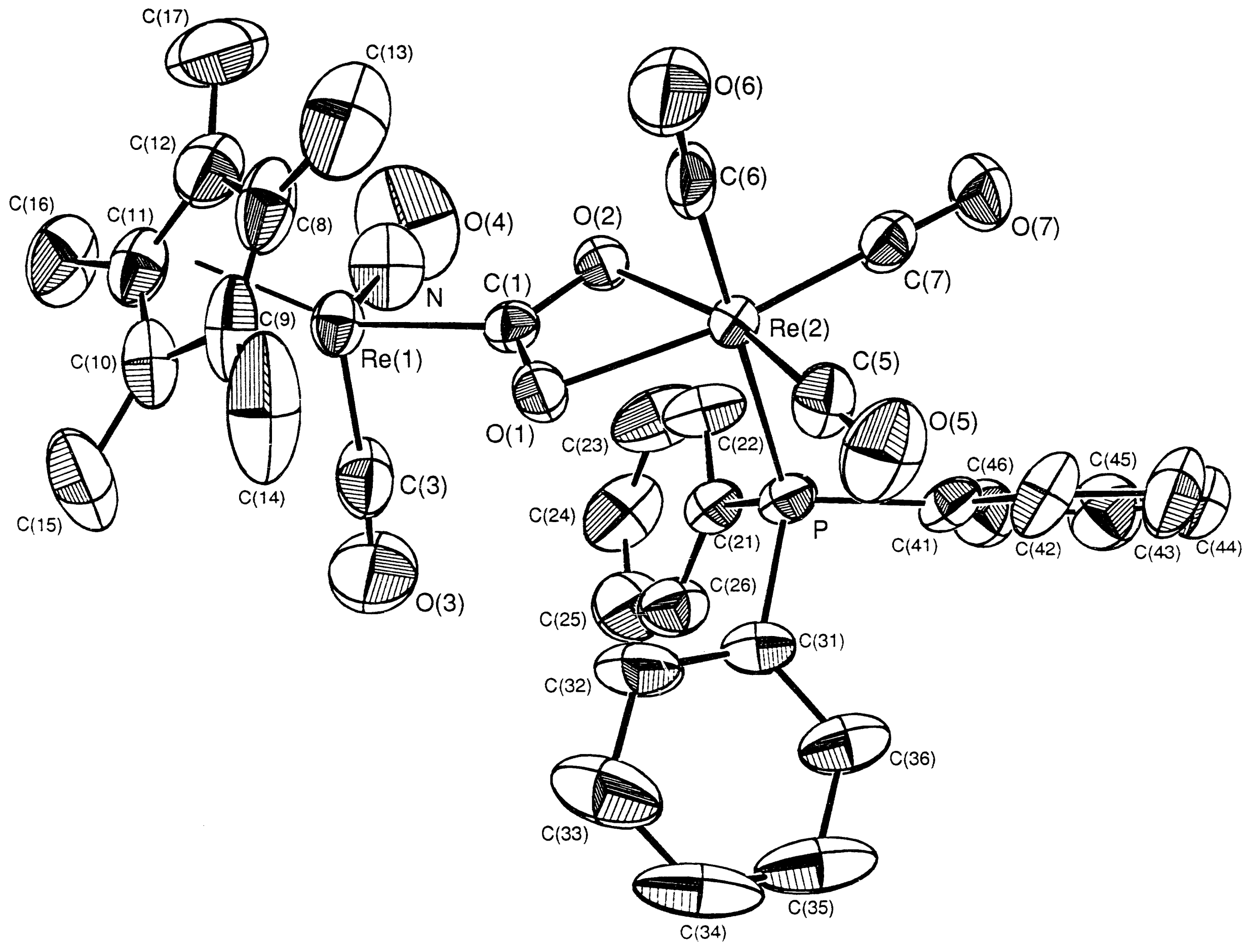




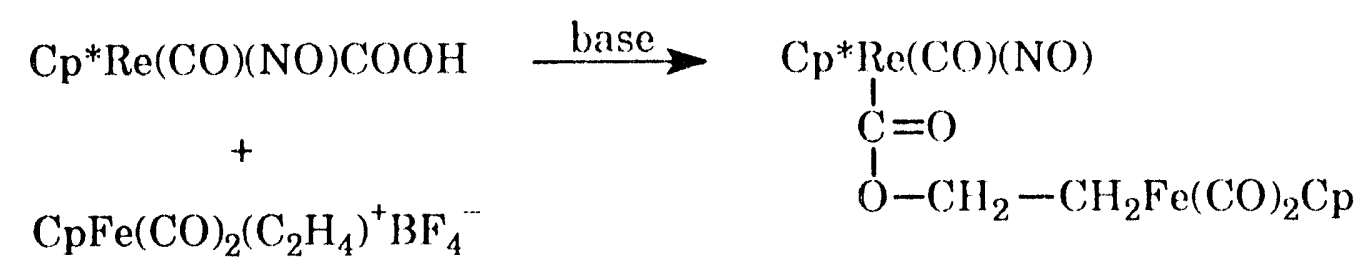

The bridged compound has been isolated and spectrally characterized.

Interestingly, it undergoes thermolysis with loss of ethylene but with apparent retention of the carboxyl group. Efrorts are in progress to fully characterize both compounds. Compounds in this series promise to be more interesting than those in the previous series.

\section{Plans for 1993-94}

Clearly there is much work in progress which will require additional effort for completion. The new rhenium metallocarboxylate has provided some interesting new compounds and its derivatives are frequently crystalline. 'This will be very helpful in expanding structure-activity correlations. Efforts will be made to prepare other $\mathrm{CO}_{2}$-bridged complexes derived from this system and to alter conditions in hopes of observing $\mu_{2}-\eta^{2}$ complexes as well.

Compounds having chelating organic carboxylato ligands [e.g., to $\operatorname{Re}(\mathrm{I})$ centers] are known to exchange one type of carboxylato ligand for another. We intend to probe the reactions of some of these with metallocarboxylates in hopes that we can access some types of $\mu_{2}-\eta^{3}$ bridging compounds which cannot be made by our current methods. For example, reaction of $\mathrm{HRe}(\mathrm{CO})_{2}\left(\mathrm{PPh}_{3}\right)_{3}$ with acetic acid yields $\operatorname{Re}(\mathrm{CO})_{2}\left(\mathrm{PPh}_{3}\right)_{2}\left(\mathrm{O}_{2} \mathrm{CCH}_{3}\right)$. Reaction of this product with chloroacetic acid provides the chloroacetate-chelated product. We will try to do similar exchange reactions with our iron and rhenium metallocarboxylates as a means of generating new $\mu_{2}-1 \eta^{3}$ products. 


\section{Publications and Presentations}

\section{Publications}

a) published

Synthesis and Characterization of $\mu_{2}-\mu^{2}$ and $\mu_{2}-\eta^{3}-\mathrm{CO}_{2}$ complexes of Iron and Rhenium, Dorothy H. Gibson, Ming Ye and John F. Richardson, J. Am.

Chem. Soc., 1992, 114, 9716.

Reactions of cis- and trans- $\left(\eta^{5}-\mathrm{C}_{5} \mathrm{H}_{5}\right) \mathrm{Mo}(\mathrm{CO})_{2}-\left[\mathrm{P}(\mathrm{OPh})_{3}\right] \mathrm{CH}_{2} \mathrm{OCH}_{3}$ with Electrophiles, Dorothy H. Gibson, elaime O. Franco and John F. Richardson, Organometallics, 1993, 12, 860.

1-Carbonyl- $\mu$-carboxylato-1 KC:2KO:2KO'- $\eta^{5}$-indenyl-2,2,2-triphenyl-1-1-

(triphenylphosphine) irontin, Dorothy H. Gibson, John F. Richardson and Okey P. Mbadike, Acta Cryst., 1993, B49, 784.

b) in preparation

Synthesis and Characterization of Rhenium Metallocarboxylates, Dorothy H. Gibson, Jayesh M. Mehta, John F. Richardson and Mark S. Mashuta.

Synthesis and Thermolysis Reactions of $\mathrm{CO}_{2}$-Bridged Bimetallic Complexes, Dorothy H. Gibson, Ming Ye, and John F. Richardson.

\section{Presentations}

$\mathrm{CO}_{2}$-Bridged Bimetallic Complexes, Dorothy H. Gibson, Ming Ye, Michael 'T. Harris, Jaime O. Franco, Okey P. Mbadike, Jayesh M. Mehta and John F. Richardson, presented at the International Conference on Carbon Dioxide Utilization, September 28, 1993 in Bari, Italy.

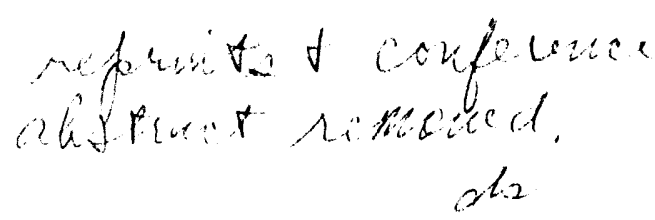



